\title{
A Study of the Aesthetic Thought and Application of "Virtual \& Real" in Chinese Ink Animation from Strolling in Aesthetics A Case Study of Feelings of Mountains and Waters
}

\author{
Xi Zhang* \\ Tiangong University, Tianjin 300387,China.
}

\begin{abstract}
Zong Baihua's Strolling in Aesthetics is known as a textbook of contemporary Chinese aesthetic theory, while "virtual \& real", as an important chapter in this book, is the core of Chinese traditional aesthetics. Its connotation of simple and natural aesthetic meaning has been applied in many fields with the rise of contemporary traditional art. The early ink animation Feelings of Mountains and Waters integrated this aesthetic conception deep into the film. In this paper, based on the analysis of Feelings of Mountains and Waters, a masterpiece of Chinese ink animation, and combined with the film, an in-depth analysis was carried out on the basic theoretical viewpoints in the "Virtual \& Real in Chinese Artistic Expression" section in Strolling in Aesthetics. Then a summary was made on the presentation of "virtual \& real" in Chinese ink animation, and a discussion was conducted on its internal association and application value with Chinese ink animation, so as to provide reference for the development of Chinese ink animation in the new era.
\end{abstract}

Keywords: Chinese Aesthetics; Ink animation; Feelings of Mountains and Waters

\section{1 "Virtual" and "Real" in Strolling in Aesthetics}

In traditional Chinese aesthetics, "virtual" and "real" are a pair of very important and complicated concepts, relating to ancient painting, calligraphy, novel, poetry, opera and other forms of artistic presentation. This aesthetic thought can be traced back to the theory of Taoism and Confucianism in the Pre-Qin Dynasty, and towards this thought, literary critics of the past dynasties had different interpretations and promotion ${ }^{[1]}$. Mr. Zong Baihua also attached great importance to this pair of concepts in his Strolling in Aesthetics, and he called it "the core issue of Chinese aesthetic thought".

In Strolling in Aesthetics, Mr. Zong discussed the relationship between "virtual" and "real". He first quoted "Only with integrity and quintessence can a presentation be called really beautiful" in Xunzi's masterpiece On Music and mentioned the difference between "integrity" and "quintessence". Then he quickly realized the conflict between them. "Can a presentation have integrity and quintessence at the same time?" However, if we focus on "integrity" and ignore "quintessence", it would be the so-called naturalism. Likewise, if we focus on "quintessence" but not "integrity", it would be abstract formalism. To address this conflict and correctly combine "virtual" and "real" to guide artistic creation, Zong Baihua referenced the metaphor of dragon painting in the preface of Tan Yi Lu which was written by Zhao Zhixin, a writer in Qing Dynasty, to discuss poetry creation. In particular, he emphasized the discussion Da Zhongguang made in his Hua Ji, in the purpose of stating that the key to preserve "integrity" and "quintessence" and at the same time draw a demarcation line with naturalism or formalism, lies in symbolism. One scale and one claw can represent a whole dragon, just like the whole world can be seen in a grain of sand. The artist accurately grasped the law of presentation of all things, and created a necessary situation by means of symbolism, "without weakening the full content of the whole", to let viewer's imagination play the role of completion, and make them feel the completeness out of absence and feel the real out of virtual ${ }^{[2]}$.

With the rise of popular culture, the beauty of "virtual \& real" has been widely applied to more and more fields of literature and arts, including poetry, prose, novels, and movies, because of its rich connotation and wide applicability and representativeness, bringing fresh experience to different fields and different audiences. Thanks to its rich philosophical thoughts and artistic conception, "virtual \& real" is assured of its place in contemporary popular literature and art. In ancient China where nature is the highest pursuit of art, "virtual \& real" has become an indispensable part of the artistic conception of classical aesthetics. With the development of contemporary culture and art, "virtual \& real", which is naturally rooted in the aesthetic thought of the Chinese nation, is becoming richer, more vivid, and more diverse. In addition to its application in calligraphy, painting, and space, "virtual $\&$ real" is gradually applied to the field of drama, film and television, evolving into an implication form with a detached attitude

Copyright (C) 2020 Xi Zhang

doi: 10.18282/1-e.v9i4.1704

This is an open-access article distributed under the terms of the Creative Commons Attribution Non-Commercial License (http://creativecommons.org/licenses/by-nc/4.0/), which permits unrestricted non-commercial use, distribution, and reproduction in any medium, provided the original work is properly cited. 
towards life and a natural and casual state of mind through the performance of traditional aesthetics. This authentic form has posed wide influence and broadened the communication channels due to its natural connection with the public. In the contemporary era, the animated films, comics and diversified forms of animation in the popular culture ports of Europe, America, Japan and South Korea have been gradually assimilated because of the increasing influence by foreign cultures. Therefore, more attention needs to put on the excavation, adaptation and production of animation works. Starting from the core of traditional Chinese aesthetic thought, the deep connotation of "virtual \& real" should be constantly explained, extended and contemplated to promote the display and dissemination of traditional Chinese aesthetic concepts in animation works.

\section{The Aesthetic Expression of "Virtual" and "Real" in Ink Animation from the Study of Feelings of
Mountains and Waters}

In the creation of Chinese animations, the "Chinese Animation School" from the 1950s to the 1980s made great achievements. The representative works of this school include The Monkey King, Nezha's Triumph Against Dragon King and Feelings of Mountains and Waters. These animated cartoons have consciously had traditional Chinese aesthetic thoughts integrated in the animation creations. For character images and scenes, the unique language of traditional aesthetic conception is often used, and the virtual and the real coexist, hovering between "like and not like"[3]. A typical representative of such virtual real works is the Feelings of Mountains and Waters which shows the Taoist philosophy and aesthetic concept of learning from nature and returning to nature in the form of an ink animation ${ }^{[4]}$.

\subsection{Aesthetics in Character Images}

The Feelings of Mountains and Waters has a distinct atmosphere of "virtual \& real" in character image design and temperament setting. Because the traditional aesthetics advocates the natural feeling of "washing away excessive magnificence" and "clear water lotus", the character images in ink animations were usually represented using ink lines in the form of freehand brushwork. Simple and natural, the characters' unique charms were highlighted with concise strokes, with the characters integrated with the artistic conception of the pictures to express the deep emotion and connotation. The character images of Feelings of Mountains and Waters are both "like and not like", both virtual and real, just like the old zither player in Figure $\mathbf{1}$ and the young fisherman learning zither in Figure 2. In the film, the characters were sketched with only a few strokes, but they are complete enough to present the character's detached and broad-minded temperament on the screen.

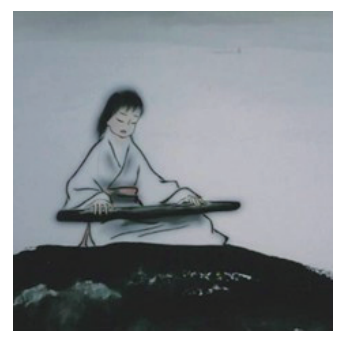

Figure 1 An old zither player Figure 2 A young fisherman

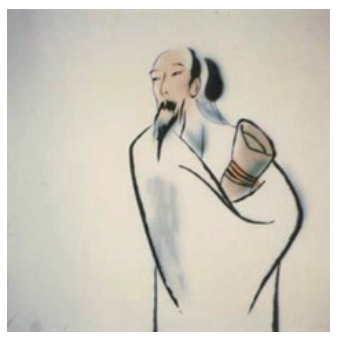

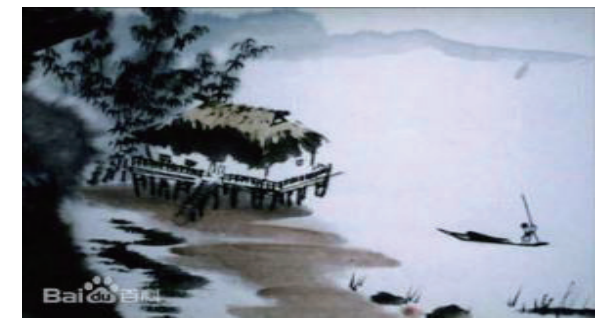

Figure 3 A scene in Feelings of Mountains and Waters

\subsection{Aesthetics in Composition of Scenes}

The Feelings of Mountains and Waters has a strong sense of "virtual" and "real" in space construction and artistic conception rendering. The story took place in a mountain where there were few people. A zither player, traveling through mountains and rivers, was in danger, which led to the plot. The choice of the place reflected Taoist's worldly outlook. The sparsely populated, open but barren valley was like a paradise, which is in line with Taoist's pursuit of seclusion. The zither player was traveling leisurely through mountains and rivers, which is not only a practice of "learning from nature", but also an interpretation of "knowing the white and keeping the black".

As to the overall processing of pictures, the scenes in the Feelings of Mountains and Waters are dominated by stillness and emptiness. The ingenious use of ink painting techniques in the picture (Figure 3) presents a scene of virtual reality. With only a few strokes, the character is already leaping off the picture to travel in the distant mountains. A boat comes from the misty river. It seems that "the air is flowing" on the screen. The character and the background are perfectly integrated to present a scene of open wilderness. Ink paintings reckon blank as inked and use water and ink to create an artistic conception of landscape which combines the virtual and the real, with a natural meaning of emptiness and wilderness. The distant mountains are entirely unreal, and the vegetations are illusory. The use of pictures and colors draws on the experience of Taoist aesthetics. The long lens in the film imitates the scattered perspective of traditional paintings to create a quiet and distant artistic conception, whereas the empty lens appearing from time to time in the film is similar to the technique of leaving blank in paintings, which extends the scene and encourages people to imagine.

\subsection{Aesthetics in Narration}

The Feelings of Mountains and Waters obviously applied "virtual \& real" in its narrative structure and content selection. With a simple narrative, the story is structured around the encounter, zither teaching, traveling in mountains and rivers together, and parting between a zither player and a young fisherman. From their meeting in adversity, accompanying each other in zither teaching and traveling, to their parting, the connections between the segments are natural, without deliberate increase of plot complexity. The narrative is plain but meaningful. The film unfolds the story with the complex of master apprentice inheritance which is deeply rooted in the nation's heart. The philosophy of "Tao Follows Nature" runs through the story, with an atmosphere 
of "virtual and real", which is embodied as the natural display of such ideas as "scenery comes from heart" and "full of love and joy " in narrative details. This can be seen from the scenes of the master and apprentice's leisurely journey to feel the music, the master's zither gifting before leaving, and the apprentice's farewell by playing music.

In the narration, Zong Baihua's understanding of "virtual and real" in Strolling in Aesthetics was referenced: "The correct definition of the combination of the virtual and the real in art" is to "turn the scenery into emotion". Emotion is neither visible nor touchable. To show this kind of virtual things, we must turn emotion into scenery and the virtual into reality. In the narrative process of the film: through the flying eagle in the sky (Figure 4), we can feel the ambition of the old zither player and his outstanding behavior like that of immortals; through the swimming fish in the water (Figure 5), we can sense the leisurely feelings of the master and the apprentice, and from the surging river, we can feel the sincere and profound feelings of the master and apprentice. In addition, at the beginning of the film, a beautiful, tranquil and peaceful atmosphere was created for the meeting of the master and the apprentice. When it comes to the parting, a scene of boundless mountains, misty rain and rolling waves was presented. There is no dialogue between the characters, but the atmosphere of "The silence speaks" and "beyond words" incisively and vividly expresses the characters' emotions and their characteristics. At the end of the film, when the fisherman and the old zither player were separated, the camera switched to the pines and cypresses swinging with the wind, which indicated the fisherman's reluctance to departure and his sadness. The young fisherman realized the true meaning of the music. The process of his perception and his inner activities were not so clear in the narrative. Instead, they were presented through the narrative of camera languages from the turbulent river to the flying eagle in the sky.

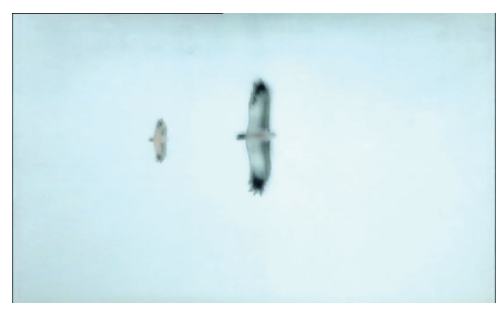

Figure 4 Soaring hawk

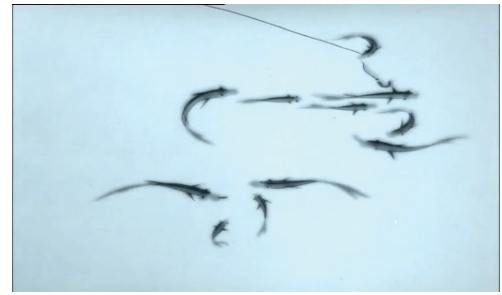

Figure 5 Swimming fish in the water

\section{The Significance and Value of the Application of "Virtual" and "Real" in the Feelings of Mountains and Waters}

\section{1 "Virtual \& Real" to the Feelings of Mountains and Waters}

From the internal relationship between the virtual and the real, the traditional Chinese aesthetic thought provides rich materials for the creation of ink animation. It pursues an aesthetic creation of "emptiness and environment" which combines emotion with scenery, blends feelings with the scene, and has an ethereal artistic conception and melodious Buddhist spirit, all of which originate from the traditional Chinese culture and form the unique characteristics of China's animated films. Through such aesthetic creation, we can have a deeper understanding that national traditional culture is no longer a conceptual symbol, but a cultural value displayed through historical precipitation and a cultural attitude and concept that a country presents to the world.

As the core of the traditional Chinese aesthetic thought, "virtual" and "real" were incisively and vividly reflected in the Feelings of Mountains and Waters. Incorporated into the characters and with the lens, "virtual \& real" was even sublimated to the core idea of the film. It is also because of the deep implementation of traditional Chinese aesthetics from the inside to the outside that the film stood out from many animated films, presented the audience an "authentic" Chinese ink animation, gained extensive recognition from the world, and won many animation awards.

\subsection{Application Value of "Virtual \& Real"}

In terms of cultural value, animated films have become a kind of culture, with strong permeability and communication and representing the culture of the national spirit. As a great creation in the history of Chinese animation, ink animation bears the mission and responsibility of transmitting culture and improves the artistic realm of Chinese animation works.

In terms of aesthetic value, "artistic conception" and "the combination of virtual and real" are one of the most important aesthetic characteristics in traditional Chinese aesthetics. No matter in traditional poetry and painting or ink animation, the expression and construction of artistic conception have high aesthetic values. Just as what Zong Baihua mentioned about the artistic realm of "between like and unlike", the dialectical unity of "metaphorical and non-metaphorical", "possible and impossible" and "speakable and unspeakable" makes "virtual and real" tend to be an unstable concept and a limited phenomenon of "unspeakable reason" in the unity of sensibility and rationality, reflecting the aesthetic characteristics of the highest aesthetic ideal of classical arts in the development of contemporary animation.

\section{Conclusion}

Ink animation, the Feelings of Mountains and Waters, embodied the Chinese traditional aesthetic fashion, applied the Chinese traditional aesthetic "virtual and real artistic conception" to the largest extent, and pushed Chinese animation to the peak of the world. This is inseparable from the persistence that the older generation of Chinese animation producers has made on drawing inspirations from the essence of Chinese traditional culture. The beauty of traditional culture and the fantasy temperament of Chinese classical romance were combined, through which this unforgettable animation was produced. Therefore, in the process of Chinese animation production, great importance must be attached to the excavation and application of traditional Chinese aesthetic thoughts. To integrate traditional aesthetic thoughts into the creation of modern animation works is not only to present the national 


\title{
Two sides of the economic effects of high-speed rail construction on small and medium-sized cities and its countermeasures
}

\author{
Meng $\mathbf{L i}^{*}$ \\ School of Economics and Management,Shanghai Maritime University,Shanghai 200000,China.
}

\begin{abstract}
With the opening of high-speed rail since 2008,China has entered the era of high-speed rail.The rapid development of high-speed rail has effectively broken through the bottleneck of insufficient capacity in China, which has produced a host of positive effects and made great contributions to China's economic development.However,the research shows that the rapid development of high-speed rail construction is greatly beneficial to the large cities,but its impact on small and medium-sized cities along the way is yet to be discussed.Therefore, it is necessary to explore the economic effects of high-speed rail construction on small and mediumsized cities and effectively deal with the negative impact brought by high-speed rail.

Keywords:Two sides of the economic effects;High-speed rail construction;Suggestions and countermeasures on positive and negative effects of high-speed rail economy

\section{Introduction}

In recent years, the rapid development of China's economy and the rapid advancement of urbanization have brought great market demand and potentials to high-speed rail construction.In recent years, the rapid development of China's high-speed rail has enabled our high-speed rail industry to change from"blank"to"catch up"and then to"lead".By the end of 2019,China's railway operating mileage will reach 139,000 kilometers,of which 35,000 kilometers are high-speed rail,ranking first in the world[1]. The construction of high-speed rail improves regional accessibility,shortens time and space distance,and plays an increasingly prominent role in promoting economic development.But at the same time,we should be soberly aware that the high-speed rail itself is not an absolute economic"growth engine",especially for a slice of small and medium-sized cities.If the advantages of small and medium-sized cities are not obvious,the environmental attraction is not strong enough,and the convenience brought by the construction of high-speed rail is not seized to accelerate their own development,the high-speed rail will even become a"corridor"to suck back the resource elements.
\end{abstract}

\section{Positive effect;Three major dividends}

\subsection{Attract superior resources to gather and produce agglomeration effect}

The construction of high-speed rail improves the accessibility of urban areas,makes the transportation more convenient,and reduces the transportation cost between regions, thus attracting material flow,talent flow, technology flow and capital flow to gather here, accelerating the agglomeration of industry and cities, and indirectly promoting economic growth.By studying the influence of high-speed rail on the service industry gathering,we can find that the redistribution of high-speed rail leads to the service industry gathering in cities along the route.Diffusion is beneficial for the service resources of core cities to be dispersed to small and medium-sized cities along the route.

Copyright (C) 2020 Meng Li

doi: $10.18282 / 1-$ e.v9i4.1705

This is an open-access article distributed under the terms of the Creative Commons Attribution Non-Commercial License (http://creativecommons.org/licenses/by-nc/4.0/), which permits unrestricted non-commercial use, distribution, and reproduction in any medium, provided the original work is properly cited.

aesthetic spirit, but also to bring an audio-visual feast to the audience. The audience perceives the essence of traditional culture and receives aesthetic edification, which will not only contribute to the development and dissemination of Chinese animation aesthetics, but also help to establish national cultural confidence and inherit national cultural spirit.

\section{References:}

[1] Baihua Zong. Aesthetic walk [M]. Shanghai: Shanghai People's publishing house, 1981.

[2] Zeman Chen. An analysis of Mr. Zong Baihua's "virtual reality" from "aesthetic walk" [J]. Ideological beauty and the times (2), 2013 (5): 55-56.

[3] An Yang. The important role of visual "language" of ink painting in national animation. Zhejiang: China Academy of fine arts, May 2008.

[4] Jun Sun. MCA. Film and animation film analysis [M]. Ocean Press, 2005.2. 